https://helda.helsinki.fi

SALSA-A dance on a slippery floor with changing partners

Reichhardt, M. P.

2017-09

Reichhardt, M P , Holmskov , U \& Meri , S 2017 , ' SALSA-A dance on a slippery floor with changing partners ' , Molecular Immunology , vol. 89 , pp. 100-110 . https://doi.org/10.1016/j.molimm.2017.05.029

http://hdl.handle.net/10138/297986

https://doi.org/10.1016/j.molimm.2017.05.029

publishedVersion

Downloaded from Helda, University of Helsinki institutional repository.

This is an electronic reprint of the original article.

This reprint may differ from the original in pagination and typographic detail.

Please cite the original version. 
Review

\title{
SALSA-A dance on a slippery floor with changing partners
}

\author{
M.P. Reichhardt ${ }^{\mathrm{a}, \mathrm{b}, *}$, U. Holmskov ${ }^{\mathrm{c}}$, S. Meri ${ }^{\mathrm{b}, \mathrm{d}, \mathrm{e}, *}$ \\ a Sir William Dunn School of Pathology, University of Oxford, Oxford, United Kingdom \\ b Department of Bacteriology and Immunology, Haartman Institute, Immunobiology Research Program, University of Helsinki, Helsinki, Finland \\ c Institute of Molecular Medicine, University of Southern Denmark, Odense, Denmark \\ ${ }^{\mathrm{d}}$ Helsinki University Central Hospital Laboratory (HUSLAB), Helsinki, Finland \\ e Humanitas University, Rozzano, Italy
}

\section{A R T I C L E I N F O}

\section{Keywords:}

Complement

Lectin

Agglutinin

Saliva

Scavenger

IgA

\begin{abstract}
A B S T R A C T
It is becoming increasingly clear that the connections between our immune system and the microbiota colonizing us have a tremendous impact on human health. A number of innate molecular defence mechanisms cooperate to selectively target unwanted microorganisms at the mucosal surfaces. Amongst others these include the complement system, IgA and the SALSA molecule. The salivary scavenger and agglutinin (SALSA), also known as deleted in malignant brain tumors 1 (DMBT1), salivary agglutinin (SAG) or gp340 is a multifunctional molecule with important functions in innate immunity, inflammation and epithelial homeostasis. The SALSA protein is expressed at most mucosal surfaces, where it is one of the most abundant proteins. In the fetal meconium and infant intestine it may constitute even up to $10 \%$ of the total protein amount. SALSA is found either directly associated with the epithelial surface or secreted into the lining fluids. In the fluid-phase SALSA interacts with a number of bacterial and viral organisms, as well as with endogenous ligands, including IgA, lactoferrin, surfactant proteins and complement components. While complement has been shown to impact the mucosal environment, this remains an area of limited research. The multiple interactions of the SALSA molecule provide a scaffold, where this potent defence system may engage in cooperative microbial clearance together with corresponding mucosal host ligands.

With its high abundance, and multiple effects on both host and microbes, the SALSA molecule is a key player in maintaining the immunological balance at the mucosal surfaces. This is further supported by observations linking the expression of different SALSA isoforms to the development of chronic inflammatory conditions, such as Crohn's disease and ulcerative colitis. This review describes the latest advances in understanding functions of SALSA and its different isoforms. Recently recognized functions are related to complement activation and regulation, endothelial development and epithelial homeostasis. In addition, we suggest mechanisms how SALSA regulates inflammation at the mucosal surfaces.
\end{abstract}

\section{Introduction}

In recent years it has become clear that the crosstalk between the host and the microbiota plays an important role in shaping the human immune system (Chu et al., 2016; Rooks and Garrett, 2016). The polarized epithelial cells and the protein contents of the mucosal secretions play a central role in the interactions with the microbiome (Cone, 2009). A state of balanced immunity is essential for human health. A weak immune response or a damaged mucosal barrier can lead to infections caused by opportunistic pathogens (Dethlefsen et al., 2007). However, a mucosal environment favouring an overreactive immune response may lead to allergies and chronic inflammation, as seen e.g. in Crohn's disease (Hugot et al., 2001; Ogura et al., 2001a).
Immunological homeostasis is maintained by the intricate network of cells and endogenous defence molecules, one of which is the salivary scavenger and agglutinin (SALSA).

SALSA has widespread functions in innate immunity, inflammation, epithelial homeostasis and tumor suppression (Kang and Reid, 2003; Ligtenberg et al., 2007; Madsen et al., 2010; Reichhardt and Meri, 2016). Originally SALSA was identified as a 300-400 kDa salivary streptococcal agglutinating protein, and named salivary agglutinin (SAG) (Ericson and Rundegren, 1983). Later, two independent groups found the protein in other tissues. A $340 \mathrm{kDa}$ glycoprotein was copurified with surfactant protein D (SP-D) from bronchoalveolar lavage fluid and named gp340 (Holmskov et al., 1997). Simultaneously, the SALSA gene was found to be deleted in several brain tumors, thus

\footnotetext{
* Corresponding authors at: Haartman Institute, University of Helsinki, Haartmaninkatu 3, \& \#8232;P.O. Box 21, 00014 Helsinki, Finland.

E-mail addresses: martin.reichhardt@path.ox.ac.uk (M.P. Reichhardt), seppo.meri@helsinki.fi (S. Meri).
} 


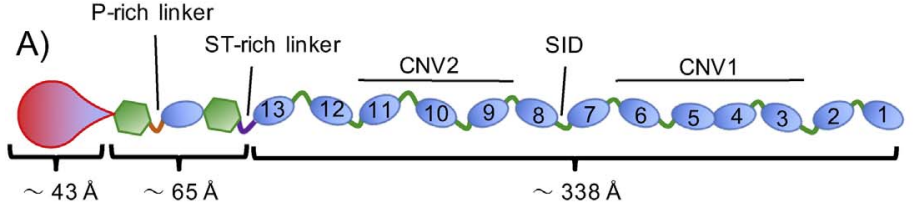

B)

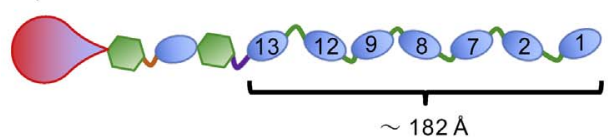

C)

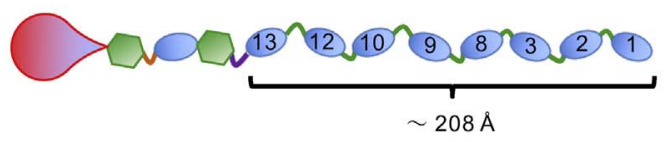

D)

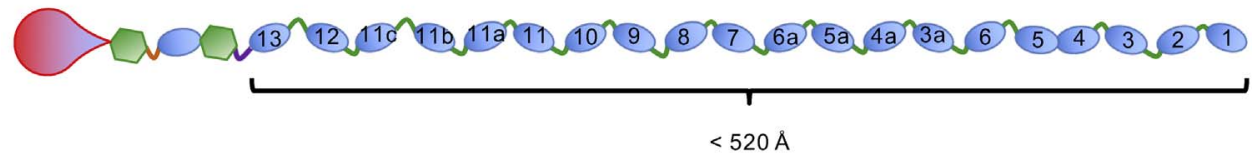

Fig. 1. SALSA structure.

Displayed is a selection of SALSA isoforms as identified by cDNA sequencing and population genetic copy number variation (CNV) studies. The isoforms are drawn to scale with predicted lengths calculated on the basis of structurally similar domains of chicken ZP3 (ZP domain), rat MASP-2 (CUB domain arrangement), and human CD5 and CD6 (SRCR domains) (Chappell et al., 2015; Feinberg et al., 2003; Han et al., 2010; Rodamilans et al., 2007)). (A) Canonical full length SALSA, as originally identified. Domains $10-11$ are up to $100 \%$ identical at the nucleotide level. (B) Shortest version of the SALSA protein as identified by CNV analysis. (C) Deletion variant associated with Crohn's disease, also referred to as $d m b t 1^{47}$ (Mollenhauer et al., 1999). (D) Longest proposed variant with duplication at the CNV1 and 5 repeats of SRCR10 at CNV2, here named 10, 11, and in accordance with the canonical full length model followed by additional identical repeats; 11a, 11b and 11c. ZP: zone pellucida, CUB: C1r/C1s, urchin embryonic growth factor and bone morphogenetic protein-1, SRCR: scavenger receptor cysteine-rich, SID: SRCR interspersed domain, ST-rich linker: serine-threonine rich linker, P-rich linker: prolinerich linker.

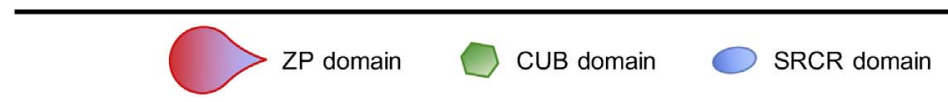

giving rise to the name 'deleted in malignant brain tumors 1' (DMBT1) (Mollenhauer et al., 1997). Currently, it appears that the various names describe the same protein expressed in different tissues. To give the protein a uniform, memorable and functionally related name a common name for the protein was recently suggested; SALSA (salivary scavenger and agglutinin) (Reichhardt et al., 2012).

\section{The SALSA protein and its isoforms}

The gene encoding the SALSA protein, the DMBT1 gene, contains 54 exons and spans $80 \mathrm{~kb}$ of the human genome. The expressed gene encodes 13 scavenger receptor cysteine-rich (SRCR) domains linked by short proline-rich segments named SRCR interspersed domains (SIDs). The SRCR domains are followed by two "C1r/C1s, urchin embryonic growth factor and bone morphogenetic protein-1" (CUB) domains surrounding the 14th SRCR domain, and finally, a zona pellucida (ZP) domain in the C-terminus (Fig. 1) (Holmskov et al., 1999; Mollenhauer et al., 1999). Evolutionarily, the 109-110 amino acid SRCR domains are highly conserved motifs that have been described in both mammals, vertebrates and even invertebrates such as blue-green algae and sponges (Mollenhauer et al., 1999; Sarrias et al., 2004; Wheeler et al., 2008). The first 13 SRCR repeats of SALSA are very homologous having 90-100\% identity at the nucleotide level (SRCR3/7 and SRCR10/11 being $100 \%$ identical). The repeats therefore form an obvious target for alternative splicing, which leads to the expression of different SALSA isoforms, each with different numbers of SRCR and SID domains (Holmskov et al., 1999; Mollenhauer et al., 1999, 2002b). Recent studies identified two distinct areas of the DMBT1 gene prone to internal copy number variation (CNV) (Polley et al., 2015). In this type of genetic variation only part of a gene (e.g. the amount of SRCR-SID repeats) varies in number between individuals. Specifically for DBMT1 two copy number variants exist, CNV1 (covering 4 SRCR domains) and CNV2 (covering an individual SRCR domain) (Polley et al., 2015). Due to the high homology between the individual SRCR domains a slight uncertainty of the specific localization of CNV1 exists. Thus, the CNV1 variation may lead to either addition or deletion of the SRCR3-6 or the SRCR4-7 regions (Mollenhauer et al., 2002c; Polley et al., 2015). CNV2 may result in $0-5$ copies of SRCR10. Thus the expressed proteins are expected to vary from 7 up to $20 \mathrm{~N}$-terminal SRCR domains (Fig. 1) (Polley et al., 2015, 2016). Several other deletions and single nucleotide polymorphisms (SNPs) have been described in the DBMT1 gene (Diegelmann et al., 2013; Sasaki et al., 2002). Variation in the numbers of expressed repeats has been found in up to $28 \%$ of normal individuals (Mollenhauer et al., 2000). At the protein level Western blotting has verified the variation in the sizes of SALSA proteins from different individuals. Moreover, the protein size appears to vary in different tissue compartments of the same individual, as well (Eriksson et al., 2007; Loimaranta et al., 2005; Reichhardt et al., 2014). However, it has been estimated that $25-45 \%$ of the molecular mass of the SALSA protein arises from glycosylation, which may explain part of the observed variation (Ericson and Rundegren, 1983; Holmskov et al., 1999). The sugar moieties on SALSA include e.g. N-glycans,sialylated Galß13GalNAc and lactosamine structures (Eriksson et al., 2007; Hartshorn et al., 2006; Oho et al., 1998). Interestingly, both ABO blood group and Lewis antigens are found differentially expressed on SALSA depending on the secretor $(\mathrm{Se}(+/-))$ status $(+/-$ expression of the $\alpha 1-2$ fucosyltransferase). $\mathrm{ABO}$ and Lewis antigens $\mathrm{b}$ and $\mathrm{y}\left(\mathrm{Le}^{\mathrm{b}}\right.$ and $\left.\mathrm{Le}^{\mathrm{y}}\right)$ were found on SALSA from $\mathrm{Se}(+)$ individuals. These sugar moieties were not found on SALSA from $\mathrm{Se}(-)$ individuals. In contrast, SALSA from the $\mathrm{Se}(-)$ individuals contained Lewis antigens a and $\mathrm{x}\left(\mathrm{Le}^{\mathrm{a}}\right.$ and $\mathrm{Le}^{\mathrm{x}}$ ) (Eriksson et al., 2007; Ligtenberg et al., 2000). A comparison of SALSA expressed in different secretions revealed additional variations in glycosylation (Eriksson et al., 2007; Schulz et al., 2002). Thus, the observed variations between the SALSA isoforms may both originate from differences in the number of SRCR/SID domains as well as differences in glycosylation (Eriksson et al., 2007; Loimaranta et al., 2005; Prakobphol et al., 2005; Reichhardt et al., 2014; Schulz et al., 2002).

\section{Expression of SALSA}

The SALSA molecule was originally isolated from mucosal secretions. Thus, most research has focused on its expression at various mucosal surfaces. However, recently several reports have shown expression of the protein also in non-epithelial tissues (see below). A full list of tissues with described expression of SALSA is shown in Table 1.

At the mucosal surfaces, SALSA is found both in the epithelium and 
Table 1

SALSA expression in human tissues and secretions.

\begin{tabular}{|c|c|c|}
\hline Tissue & Location & Evidence \\
\hline \multicolumn{3}{|l|}{ Adult } \\
\hline Bone marrow & Not known & RT-PCR (Mollenhauer et al., 2000) \\
\hline Brain & $\begin{array}{l}\text { Purkinje cells, granular layer, some astrocytes and neuronal cells, perivascular } \\
\text { macrophages }\end{array}$ & $\begin{array}{l}\text { RT-PCR, IHC (Holmskov et al., 1999; Mollenhauer et al., 1997, } \\
\text { 2000) }\end{array}$ \\
\hline Colon & Epithelium & IHC (Mollenhauer et al., 2001) \\
\hline Duodenum & Enterocytes, crypt cells, Brunner's glands & IHC (Mollenhauer et al., 2001) \\
\hline Esophagus & Epithelium, mucus glands & IHC (Mollenhauer et al., 2001, 2002a) \\
\hline Eye & Acinar cells of lacrimal glands, conjunctival epithelium & RT-PCR, IHC (Jumblatt et al., 2006) \\
\hline Female genital tract & Epithelium & IHC (Stoddard et al., 2007) \\
\hline Gallbladder & Epithelium & IHC (Mollenhauer et al., 2002a) \\
\hline Heart tissue & Endothelium, myocytes & RT-PCR (Muller et al., 2009) \\
\hline Kidney & Collecting duct epithelium & RT-PCR (Holmskov et al., 1999) \\
\hline Liver & Hepatocytes & IHC (Mollenhauer et al., 2001) \\
\hline Lung & Epithelium, macrophages & RT-PCR, IHC (Holmskov et al., 1999; Mollenhauer et al., 1997) \\
\hline Lymph node & Not known & RT-PCR (Mollenhauer et al., 2000) \\
\hline Mammary gland & Epithelium & RT-PCR, IHC (Braidotti et al., 2004; Holmskov et al., 1999) \\
\hline Pancreas & Langerhans islets, exocrine acinar cells, pancreatic ducts & RT-PCR, IHC (Holmskov et al., 1999; Mollenhauer et al., 2001) \\
\hline Prostate & Not known & RT-PCR (Holmskov et al., 1999) \\
\hline Salivary glands & Epithelium & RT-PCR, IHC (Holmskov et al., 1999; Mollenhauer et al., 2001) \\
\hline Sinus & Serous glands & RT-PCR, IHC (Kim et al., 2007) \\
\hline Skin & Epithelium & IHC (Mollenhauer et al., 2002a) \\
\hline Small intestine & Epithelium & $\begin{array}{l}\text { RT-PCR, NB, IHC (Holmskov et al., 1999; Mollenhauer et al., } \\
\text { 1997) }\end{array}$ \\
\hline Spleen & Not known & RT.PCR (Mollenhauer et al., 2000) \\
\hline Stomach & Epithelium, gastric glands & $\begin{array}{l}\text { RT-PCR, IHC (Holmskov et al., 1999; Mollenhauer et al., 2001, } \\
\text { 2002a) }\end{array}$ \\
\hline Testis & Not known & RT-PCR (Holmskov et al., 1999) \\
\hline Thymus & Not known & RT-PCR (Mollenhauer et al., 2000) \\
\hline Tonsils & Epithelium & IHC (Mollenhauer et al., 2002a) \\
\hline Trachea & Serous cells & RT-PCR, IHC (Holmskov et al., 1999; Thornton et al., 2001) \\
\hline Uterus & Not known & RT-PCR (Holmskov et al., 1999) \\
\hline \multicolumn{3}{|l|}{ Fetus } \\
\hline Intestine & Epithelium & IHC (Mollenhauer et al., 2000) \\
\hline Kidney & Collecting duct epithelium & IHC (Mollenhauer et al., 2000) \\
\hline Lung & Not known & NB (Mollenhauer et al., 1997) \\
\hline Skin & Epithelium, epidermis & IHC (Mollenhauer et al., 2000, 2002a) \\
\hline \multicolumn{3}{|l|}{ Secretions } \\
\hline Bronchoalveolar lavage & & WB (Holmskov et al., 1997) \\
\hline Pancreatic juice & & MS (Gronborg et al., 2004) \\
\hline Respiratory mucosal secretions & & WB (Thornton et al., 2001) \\
\hline Saliva & & MS (Ligtenberg et al., 2001) \\
\hline Sinus mucosa & & WB (Kim et al., 2007) \\
\hline Tear fluid & & MS (Schulz et al., 2002) \\
\hline
\end{tabular}

IHC, Immunohistochemistry; NB, Northern blotting; WB, Western blotting; RT-PCR, Reverse transcriptase polymerase chain reaction; MS, Mass spectrometry.

in the secretory glands of the lungs, trachea, oral cavity, esophagus, stomach, small and large intestine, pancreas, gallbladder, mammary glands, vagina and cervix (Braidotti et al., 2004; Holmskov et al., 1999; Kang et al., 2002; Mollenhauer et al., 1997, 2000, 2001; Stoddard et al., 2007; Thornton et al., 2001). Both glandular and epithelial cells have been shown to produce the protein and secrete it into the surrounding fluids, such as saliva, tear fluid, respiratory mucosal secretions, pancreatic juice, breast milk and amniotic fluid (Ericson and Rundegren, 1983, Gronborg et al., 2004; Holmskov et al., 1997; Reichhardt et al., 2014; Ronellenfitsch et al., 2012; Schulz et al., 2002; Thornton et al., 2001).

In recent studies SALSA was estimated to make up $10 \%$ of the total protein content in meconium and in saliva of young children ( $<3$ years). This makes SALSA one of the most abundant proteins on these mucosal surfaces in early life, highlighting its important and apparently protective role at this stage (Reichhardt et al., 2014; Sonesson et al., 2011).

\section{Binding of SALSA to microbes}

Although the human body is virtually sterile at birth, it is immediately colonized by a multitude of microorganisms from the surrounding environment, and in particular from the maternal vaginal flora (Levy, 2007; Tlaskalova-Hogenova et al., 2004). Indeed, some studies claim that bacterial colonization may occur already inside the amniotic cavity (Bearfield et al., 2002; Jimenez et al., 2008). While we exist in a mutualistic relationship with most of the microbial colonizers, a strict regulation of the antimicrobial response is essential for the development of the microbiota in early life.

SALSA has been shown to bind and agglutinate a broad spectrum of bacteria, including Actinomyces odontolyticus, Helicobacter pylori, Salmonella enterica serovar Typhimurium, Staphylococcus aureus, Bifidobacterium lactis, a number of lactobacillus strains, and as well many types of streptococci (Table 2) (Haukioja et al., 2008; Jumblatt et al., 2006; Loimaranta et al., 2005; Prakobphol et al., 2000; Rosenstiel et al., 2007). Also the influenza A virus (IAV) and human immunodeficiency virus type 1 (HIV-1) have been shown to bind SALSA (Hartshorn et al., 2003; Nagashunmugam et al., 1998). Studies with SALSA orthologues from other mammalian species have identified additional binding partners, such as Haemophilus influenzae, Klebsiella oxytoca and Streptococcus pneumoniae (Madsen et al., 2003).

A main effector function of the SALSA molecule is simply microbial agglutination. This is an efficient mechanism for inhibiting the microbial colonization as has been shown for $S$. enterica, IAV and HIV-I (Hartshorn et al., 2003; Nagashunmugam et al., 1998; Rosenstiel et al., 2007; Wu et al., 2003). However, the specific ability of the protein to 
Table 2

Endogenous and microbial ligands of SALSA. The listed ligands have been found to bind either human SALSA, the murine-ortholog of SALSA or the recombinantly expressed bacterial binding peptide, SRCRP2.

\begin{tabular}{|c|c|c|}
\hline \multicolumn{2}{|c|}{ Endogenous ligand } & Suggested functional relevance \\
\hline \multicolumn{2}{|l|}{$\mathrm{C} 1 \mathrm{q}$} & Complement regulation (Boackle et al., 1993) \\
\hline \multicolumn{2}{|l|}{ MBL } & Complement regulation (Reichhardt et al., 2012) \\
\hline \multicolumn{2}{|l|}{ Ficolins } & Complement regulation (Reichhardt et al., 2012) \\
\hline \multicolumn{2}{|l|}{ SpD } & Microbial agglutination (Holmskov et al., 1997) \\
\hline \multicolumn{2}{|l|}{ SpA } & Microbial agglutination (Tino and Wright, 1999) \\
\hline \multicolumn{2}{|l|}{ IgA } & Microbial agglutination (Ericson and Rundegren, 1983) \\
\hline \multicolumn{2}{|l|}{ Lactoferrin } & Mucosal surfaces, bacterial binding (Mitoma et al., 2001) \\
\hline \multicolumn{2}{|l|}{ DNA } & Inflammation (End et al., 2009) \\
\hline \multicolumn{2}{|l|}{ Heparan sulfate } & Inflammation (End et al., 2009) \\
\hline \multicolumn{2}{|l|}{ Trefoil factors } & Tissue homeostasis (Thim and Mortz, 2000) \\
\hline \multicolumn{2}{|l|}{ MUC5B } & Microbial agglutination (Wickstrom et al., 2000) \\
\hline \multicolumn{2}{|l|}{ Erythrocytes } & Aggregation (Muller et al., 2009) \\
\hline \multicolumn{2}{|c|}{ Platelets } & Aggregation (Muller et al., 2009) \\
\hline \multicolumn{2}{|c|}{ EGF, Delta-like 4, Vascular endothelial growth factor } & Endothelial cell adhesion, proliferation and reparative angiogenesis (Muller et al., 2012) \\
\hline \multicolumn{2}{|c|}{ Galectin-3 } & Cell differentiation (Muller et al., 2012; Roldan and Marini, 2013; Rossez et al., 2011) \\
\hline \multicolumn{2}{|c|}{ Fibrin/Fibrinogen } & Not known (Muller et al., 2009) \\
\hline \multicolumn{2}{|c|}{ Fibronectin } & Not known (Reichhardt et al., 2016) \\
\hline Microbe & \multicolumn{2}{|l|}{ Specific strains } \\
\hline Streptococcus: & \multicolumn{2}{|c|}{$\begin{array}{l}\text { S. pyogenes, S. agalactiae, S. pneumonia, S. mutans, S. mitis, S. oralis, S. salivarius, S. gordoni, S. crista, S } \\
\text { suis (Gunput et al., 2015; Loimaranta et al., 2005; Madsen et al., 2003; Prakobphol et al., 2000) }\end{array}$} \\
\hline Lactobacillus: & \\
\hline Other bacteria: & \multicolumn{2}{|c|}{$\begin{array}{l}\text { Staphylococcus aureus, Bifidobacterium, Actinomyces, Salmonella enterica serovar Typhimurium, Helicobacter pylori, Haemophilus influenzae, Klebsiella oxytoca } \\
\text { (Haukioja et al., 2008; Jumblatt et al., 2006; Loimaranta et al., 2005; Madsen et al., 2003; Prakobphol et al., 2000; Rosenstiel et al., 2007) }\end{array}$} \\
\hline Viruses: & \multicolumn{2}{|c|}{ HIV, IAV (Hartshorn et al., 2003, Nagashunmugam et al., 1998) } \\
\hline
\end{tabular}

bind various microbes is dependent on the physical location of the protein. S. mutans is the causative agent of dental caries, while viridansgroup streptococci are part of the commensal oral flora. The binding of SALSA to streptococci is mediated through interactions with the streptococcal surface protein antigen I/II (AgI/II) (Brady et al., 1992; Demuth et al., 1990). Different parts of the AgI/II molecule are engaged in the interactions with either fluid-phase or surface-bound host molecules. These protein domains vary between streptococcal species (Jenkinson and Demuth, 1997). In the fluid phase SALSA was shown to agglutinate certain streptococcal strains. However, when SALSA was directly associated with a surface, such as the hydroxyapatite of the teeth, SALSA no longer bound these microbes (Loimaranta et al., 2005). In contrast, other streptococcal strains exclusively adhered to the surface bound protein (Loimaranta et al., 2005). This binding specificity was found to vary even for strains within the same streptococcal species. The binding may be linked to the alternate binding ability of AgI/ II. Fluid-phase SALSA was also shown to agglutinate and clear group B streptococci. However, group B streptococci were able colonize the human salivary pellicle utilizing pili in a solid-phase specific binding to SALSA on the tooth surface (Brittan and Nobbs, 2015). Thus, the characteristics and localization of the SALSA-microbe binding sites strongly affect the outcome for the microbe, and determine if it will colonize the human surface or if it will be agglutinated in the fluid phase and excreted.

Previous work investigating the bacterial binding properties of SALSA identified a peptide sequence within each SRCR domain responsible for the agglutination of most bacterial ligands. This peptide sequence (RVEVLYxxxSW), designated SRCR-peptide 2 (SRCRP2), is found in an outer surface loop that is homologous in all the SRCR domains (Bikker et al., 2002, 2004; Leito et al., 2008). However, contrasting data arose from a recent study utilizing recombinant forms of SRCR domains $1-3$ in binding assays with several AgI/II protein homologs (Purushotham and Deivanayagam, 2014). The authors found that the binding of an individual SALSA SRCR domain to AgI/II required a minimum of two distinct binding sites, without an overlap with the SRCRP2. Most binding interactions with SALSA appear to be calcium dependent (Loimaranta et al., 2005; Madsen et al., 2003; Reichhardt et al., 2012). The addition of calcium to the recombinant
SRCR domains 1-3 induced a conformational change. This structural change was, however, stronger for the surface-immobilized SRCR domains than to the soluble domains (Purushotham and Deivanayagam, 2014). The differential binding of various microbial ligands could thus be a product of different protein conformations induced by calcium.

The ability of SALSA to agglutinate bacteria is an important innate defence mechanism. However, the ability of certain microbes to bind the surface-immobilized SALSA can also have detrimental effects on human health. In a study of dental caries certain SALSA-phenotypes correlated with both adhesion of $S$. mutans and the development of dental caries (Jonasson et al., 2007). There was, however, a difference in this correlation, when comparing different SALSA isoforms. For HIVinfection, vaginal transmission of the virus is often much more successful than oral transmission (Yu and Vajdy, 2010). In the mouth the secreted salivary SALSA protein was found to interfere with oral transmission of the HIV-1 particles. However, SALSA expressed on the vaginal epithelium was found to aggregate the virus close to the epithelial surface. Thereby, SALSA had an enhancing effect on the infectivity of the virus (Stoddard et al., 2007). In addition, both antibodies and peptides that block the SALSA-HIV-1 interactions also inhibit HIV-1 transcytosis from the apical to the basolateral epithelial cell layer (Stoddard et al., 2009). These findings suggest that some microbes have evolved mechanisms to exploit SALSA to infect the human body.

Another example of an immune-compromising effect of SALSA is its interaction with the influenza A virus (IAV). Fluid-phase SALSA agglutinates IAV particles and inhibits their infectivity (Hartshorn et al., 2003). IAV binds specifically to sialic acid carbohydrate ligands in the SID-regions of SALSA. SALSA thus functions as a $\gamma$-inhibitor preventing IAV hemagglutinin from binding cellular receptors on the human host (Hartshorn et al., 2006; White et al., 2009). While the anti-IAV activity of SALSA is mainly carried out in concert with other endogenous molecules, such as SP-D, certain glycoforms of SALSA were shown to bind strongly to the carbohydrate recognition domain of SP-D and thus antagonize the anti-viral effect (Hartshorn et al., 2006). The specific binding properties of the SALSA molecule, which may both vary with localization of the protein as well as between the individual iso- and glycoforms, can greatly affect which microbes are capable of colonizing 
a particular surface or not. The variations in SALSA may therefore have implications for the composition of the local microbiome and the state of the inflammatory environment. Consequently, this may affect the tight regulation of the immunological balance at the mucosal surfaces.

\section{Endogenous ligands of SALSA}

A number of interactions have been described between the SALSA protein and other endogenous molecules. The binding partners include secretory IgA, surfactant proteins A (SP-A) and D (SP-D), lactoferrin, fibrin/fibrinogen, fibronectin, trefoil factors, mucin-5B, galectin-3, epidermal growth factor (EGF), vascular endothelial growth factor (VEGF), C1q, mannose binding lectin (MBL) and ficolins 1-3 (see Table 2 for a complete list) (Boackle et al., 1993; Holmskov et al., 1997; Madsen et al., 2013; Muller et al., 2009, 2012; Oho et al., 2004; Reichhardt et al., 2012, 2016; Rundegren and Arnold, 1987; Thim and Mortz, 2000; Thornton et al., 2001; Tino and Wright, 1999). In body secretions SALSA has been found to oligomerize into larger complexes, either alone or through interactions with the above mentioned ligands (Crouch, 2000; Madsen et al., 2010; Oho et al., 1998; Young et al., 1997). Most interactions appear to be calcium-dependent, and indeed a recent work demonstrated that the SRCR domains of SALSA have an increased structural stability in the presence of increasing calcium concentrations (Purushotham and Deivanayagam, 2014). Calcium is expected to be important for ligand interactions of both CUB and SRCR domains. Both CUB and SRCR domains may thus affect SALSA-ligand interactions as well as SALSA polymerization (Andersen and Moestrup, 2014).

\subsection{SALSA and complement}

In recent years several studies have identified SALSA as a novel regulator of the complement system (Boackle et al., 1993; Gunput et al., 2015; Leito et al., 2011; Reichhardt et al., 2012). The complement system consists of more than 40 soluble and surface-bound proteins with established immunological functions including anti-microbial defence, immune regulation, clearance of apoptotic cells, immune complexes and debris, as well as cell signalling (Dunkelberger and Song, 2010; Freeley et al., 2016; Meri and Jarva, 1998; Ricklin et al., 2010). Targeting of foreign and altered self-structures by the complement system leads to deposition of opsonins (e.g. C1q, C3b, iC3b and C4b), the complement membrane attack complex (MAC) and the production of potent pro-inflammatory mediators, such as C3a and C5a (Markiewski et al., 2007; van Lookeren Campagne et al., 2007; Walport, 2001; Wetsel, 1995). The complement system is activated by three distinct pathways; the classical, the lectin and the alternative pathways. The classical and lectin pathways are activated by binding of $\mathrm{C1q}$ (classical pathway) or mannose binding lectin (MBL), ficolins or the heteromeric complex CL-K1/CL-L1 (lectin pathway) to their respective targets (Henriksen et al., 2013; Wallis et al., 2010). Target-binding by these molecules induces conformational changes and proteolytic cleavages that activate the associated serine proteases, C1r/s and MBL-associated serine proteases 1 and 2 (MASP1 and MASP2), for the classical and the lectin pathways, respectively (Bally et al., 2009; Phillips et al., 2009). Activated C1s or MASP2 subsequently cleave the next complement components C4 and C2 to form the classical/lectin pathway C3 convertase C4b2a. This in turn will activate C3 and C5 to generate C3b and C5b as well as the fluid-phase components C3a and C5a (Wallis et al., 2010). In the alternative pathway $\mathrm{C} 3$ is activated by the $\mathrm{C} 3 \mathrm{bBb}$ enzyme, where $\mathrm{Bb}$ is the product of factor $\mathrm{D}$ mediated cleavage of factor B. C3b can deposit covalently to surfaces, and the alternative pathway can amplify activation on targets recognized as non-self (Meri, 2016).

Complement is mainly a system that operates in blood. However, during certain conditions blood leaks onto the mucosal surfaces, such as in the oral cavity or the airways (Boackle, 1991; Persson et al., 1991). This happens in everyday situations such as tooth brushing, but can be particularly observed during inflammation of the mucosa, as observed in the oral cavity with gingivitis and periodontal disease, or in the airways with cystic fibrosis (Boackle, 1991; Hoek et al., 2002; Negut et al., 2007; Norkina et al., 2004; Sass et al., 2015). Very little is known about how complement is regulated in this non-parenteral environment. When complement proteins enter the mucosa they may interact with endogenous molecules such as SALSA.

SALSA binds directly to C1q, MBL and all three ficolins (Boackle et al., 1993; Gunput et al., 2015; Leito et al., 2011; Reichhardt et al., 2012). Surface-attached SALSA was shown to activate the complement system both through the interaction with C1q and MBL. In addition, residual activation observed in ELISA-based assays was suggested to arise from the interactions with the ficolins (Boackle et al., 1993; Gunput et al., 2015; Leito et al., 2011; Reichhardt et al., 2012). However, as observed for microbial agglutination, activation of complement also appears to depend on the specific localization of SALSA. Thus, when SALSA was free in serum, it was shown to inhibit complement activation (Gunput et al., 2016; Reichhardt et al., 2012). The dual effects of SALSA on the complement system may appear contradictory at first glance. However, a likely explanation could be that SALSA, when bound to a surface, may direct complement activation against certain targets, like microbes. In contrast, SALSA binding to complement components in the fluid phase may prevent their binding to microbial targets and thus inhibit complement activation. SALSA may therefore be involved in an important mechanism underlying immunological discrimination of targets to be cleared vs. structures to be tolerated. Interestingly, the interaction with MBL appears to be dependent on the secretor status, i.e. the presence of distinct carbohydrate moieties on SALSA such as ABO and Lewis antigens (Gunput et al., 2015). In contrast, the lectin pathway inhibition of fluid phase SALSA does not seem to depend on secretor status. (Gunput et al., 2016). This presents a mechanism for individual differences in the ability to utilize SALSA for complement regulation. In the future, it will be interesting to investigate this particular mechanism in relation to both infections and inflammatory conditions.

\subsection{SALSA and IgA}

SALSA and IgA are patrolling the mucosal surfaces together. Both are provided in high amounts to infants, e.g. through breast milk (Ronellenfitsch et al., 2012). In saliva the native form of SALSA is found directly complexed with dimeric IgA (Ericson and Rundegren, 1983). Together, the two proteins were shown to mediate the agglutination of $S$. mutans, although the main binding ability was ascribed to SALSA (Ligtenberg et al., 2004; Oho et al., 1998; Rundegren and Arnold, 1987). Studies identified the previously discussed SRCRP2 peptide of SALSA as the binding site for both IgA and $S$. mutans (Ligtenberg et al., 2004). However, these interactions did not appear to be competing. Rather, the complexing of SALSA and IgA was shown to enhance the bacterial agglutination (Rundegren and Arnold, 1987). Interestingly, IgA has also been shown to interact with MBL and induce complement activation (Roos et al., 2001). Together, SALSA, IgA and MBL could form a potent anti-microbial network. The effect of SALSA on ficolins and $\mathrm{C} 1 \mathrm{q}$ could lead to a redundancy in this system, ensuring effective clearance even in the case of MBL deficiency.

\subsection{SALSA and surfactant proteins}

SALSA also binds directly to the two surfactant protein lectins SP-A and SP-D (Holmskov et al., 1997; Tino and Wright, 1999). They both belong to the protein family of collectins, i.e. have a collagen-like tail and a carbohydrate binding globular domain. The lectin domains of SPD and SP-A bind SALSA in a calcium-dependent manner (Holmskov et al., 1997; Tino and Wright, 1999). Both SP-D and SP-A are molecules expressed at the mucosal surfaces with known microbial agglutinating functions (Hakansson and Reid, 2000; Holmskov et al., 2003). In vitro, 
binding of SP-D to influenza A (IAV) was shown to induce a strong respiratory burst response in neutrophils (White et al., 2005). Interestingly, the interaction of SALSA with SP-D resulted in a reduced response. This suggests that SALSA may function to limit a potentially harmful respiratory burst response, while ensuring an increased clearance of the infecting virus (Madsen et al., 2010; White et al., 2005). This could thus be an additional mechanism of SALSA to assist microbial clearance while hindering an exacerbated immunological response.

\subsection{SALSA and lactoferrin}

Lactoferrin is a protein found at the mucosal surfaces and in secretions, such as breast milk and tear fluid. Like SALSA, lactoferrin has been shown to influence cell differentiation, antimicrobial defence and inflammation (Ward et al., 2005). Lactoferrin modulates the immunological environment by chelating iron, an essential nutrient for most microorganisms. In addition, proteolysis of lactoferrin produces smaller peptides with direct antimicrobial effects (Groenink et al., 1999; Singh et al., 2002). Both the human and the bovine forms of lactoferrin have been found to interact with SALSA, and again the interaction site was suggested to be the SRCRP2 peptide (End et al., 2005; Ligtenberg et al., 2004; Mitoma et al., 2001). However, whereas the interaction between SALSA and IgA increased bacterial agglutination, the binding of SALSA to lactoferrin was shown to inhibit this effect (Ligtenberg et al., 2004; Mitoma et al., 2001).

\subsection{Multiple ligand interactions}

A key to understanding the function of SALSA is not only its multiple interactions, but more importantly: which of these would occur at the same time. The described complexing of SALSA and IgA and the potential co-operative effect it has on streptococcal agglutination suggests that SALSA binds both IgA and the bacteria simultaneously (Ericson and Rundegren, 1983; Ligtenberg et al., 2004; Oho et al., 1998; Rundegren and Arnold, 1987). As SALSA apparently can polymerize, it may generate large protein complexes with multiple bacterial binding sites (Crouch, 2000). This could lead to efficient bacterial agglutination. In addition, the interactions with complement proteins would suggest that microbe-bound SALSA can target complement activation to the microbial surfaces and thus assist microbial killing (Boackle et al., 1993; Gunput et al., 2015; Leito et al., 2011; Reichhardt et al., 2012). If the mucosal barrier is breached, SALSA could both target complement attack to the microbial surface, and function as a bridging molecule to attract other agglutinating proteins such as IgA and surfactant proteins. These, in turn could limit the mobility of the microbes and thus reduce their infectivity (Fig. 2). This form of bridging and multi-complexing function would provide an evolutionary explanation for the multiple copies of the highly homologues SRCR domains that SALSA contain. They may simply be essential for multiple interactions.

\section{SALSA in disease}

The interactions of SALSA with the intestinal microflora and innate immune components makes SALSA an obvious candidate to influence the disease development and prognosis of inflammatory mucosal diseases. Indeed, increased SALSA expression has been observed in the epithelium of several chronic inflammatory conditions, including chronic sinusitis, cystic fibrosis in addition to Crohn's disease (CD) and ulcerative colitis (UC) (Hamm et al., 2010; Kim et al., 2007; Madsen et al., 2013; Renner et al., 2007; Rosenstiel et al., 2007). The stimulation of epithelial cell lines with phorbol 12-myristate 13-acetate and dextran sodium sulphate, two compounds used to mimic pathological inflammatory conditions, as well as direct induction by pro-inflammatory stimuli such as lipopolysaccharide (LPS), muramyl dipeptide and tumor necrosis factor $\alpha$ (TNF- $\alpha$ ) led to enhanced expression of SALSA in the affected tissue (Kang et al., 2002; Renner et al., 2007;
Rosenstiel et al., 2007). These findings show that an increased expression of SALSA is part of the normal inflammatory response of the epithelium.

\subsection{SALSA in inflammatory bowel disease}

Inflammatory bowel disease (IBD) constitutes the conditions CD and UC. Both diseases are characterized by a chronic inflammation of the intestinal mucosa, although the locations and types of inflammation are different. A steep increase in the incidence of IBD means that up to 1 in 180 adults in the Western world are now affected (Molodecky et al., 2012). The etiologies of both CD and UC are currently unknown. Accumulating data suggests that a dysregulation of the immune response towards the colonizing microflora in genetically susceptible individuals is involved (Garcia Rodriguez et al., 2006; Porter et al., 2008; Van Limbergen et al., 2009).

The cytokines IL-22 and IL-27 have been found to exacerbate mucosal inflammation (Diegelmann et al., 2012; Sugimoto et al., 2008; Zenewicz et al., 2008). IL-22 stimulation leads to increased production of IL- 6 and IL- 8 in the gastrointestinal mucosa, and IL-22 production has been found to be increased in CD (Andoh et al., 2005; Brand et al., 2006). Likewise, both IL-27 and its receptor are upregulated in inflamed intestinal tissue and CD (Diegelmann et al., 2012). IL-22 and IL-27 were shown to induce SALSA expression through STAT3, NFkB, ATF-2 and CREB1 signalling, and the enhanced expression of IL-22 and IL-27 in the inflamed mucosa correlated directly to increased SALSA levels (Diegelmann et al., 2012; Fukui et al., 2011; Xu et al., 2015).

Nucleotide-binding oligomerization domain 2 (NOD2) is involved in the intracellular recognition of microbial targets and is one of the major CD susceptibility genes (Ahmad et al., 2002; Hugot et al., 2001; Ogura et al., 2001b). Together with TLR4 activation, stimulation of NOD2 was also shown to directly induce SALSA expression (Rosenstiel et al., 2007). As for IL-22, this was mediated through NFkB signaling. While inflammatory and microbial agents induce SALSA expression by the epithelium, it was shown that SALSA itself appears to function as part of a negative feedback mechanism. In a study of epithelial response to $S$. enterica-derived LPS and muramyl dipeptide it was found that the presence of SALSA inhibited IL-8 secretion and TLR4 activation (Rosenstiel et al., 2007). A similar effect was described for cells of the myeloid cell line THP-1 (Rosenstiel et al., 2007). Although SALSA is secreted as part of an inflammatory response by epithelial and other mucosal secretory cells, the function of SALSA may be important for controlling inflammation. SALSA assists the immunological clearance at the mucosal surfaces without provoking an exacerbated inflammation. In the case of chronic inflammation, it is therefore not surprising that genetic data suggests that insufficient SALSA function may be linked to disease.

A genetic deletion variant of the above described CNV1 has been directly associated with CD (Renner et al., 2007). The study showed by CNV association studies that the expression of a SALSA isoform lacking the SRCR4-7 region ( $d m b t 1^{47-/-}$ ) made individuals susceptible to CD with an odd's ratio of 1.75 . The lack of these SRCR domains could lead to weaker bacterial binding and bacterial clearance, which consequently would shift the anti-bacterial response towards increased mucosal inflammation. This study was performed on an Italian cohort and suggested that SALSA could be used as a clinical marker for the disease (Polley et al., 2016; Renner et al., 2007). In contrast, however, a recent study analysing three northern European cohorts was unable to confirm the association between CNV1 deletion and CD (Polley et al., 2016). In addition to the $d m b t^{47-/-}$ isoform, another study identified a single nucleotide polymorphism (SNP) (rs2981804) that was also found to correlate with CD (Diegelmann et al., 2013). This mutation is in a noncoding part of the DMBT1 gene, but alters the binding of the transcription factors CREB1 and ATF-2, thus leading to decreased SALSA expression. So although it currently remains unclear which exact mutations are responsible for the involvement in chronic inflammation, it 


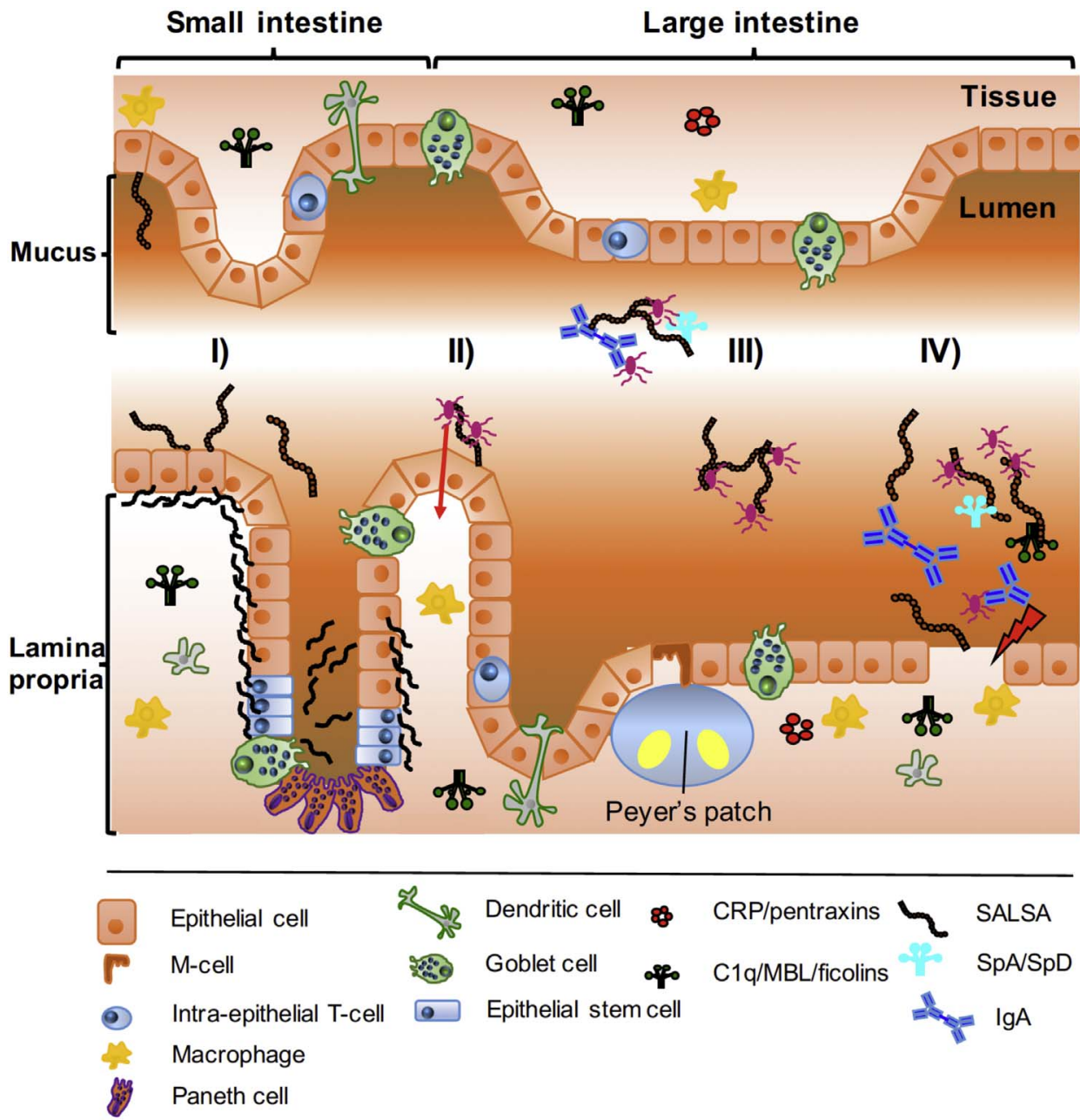

Fig. 2. Functions of SALSA at the mucosal surfaces exemplified by the gut.

(I) SALSA is produced by epithelial cells as well as various serous cells lining the glands and crypts of the mucosa. SALSA is secreted both to the basal and apical membranes of most mucosal epithelial cells. Strong expression is observed in the developing epithelium and the crypts of the small intestine. (II) The SALSA molecule binds a number of microorganisms, and while associated to the epithelial surface this may lead to increased transcytosis of certain microbes. (III) In the fluid phase SALSA agglutinates microbes, keeping them from colonizing the mucosal epithelium. This scavenging function is carried out in cooperation with endogenous ligands of SALSA, such as IgA, SP-A, SP-D and lactoferrin. (IV) In the case of epithelial damage mucosal components may mix with tissue cells and proteins. SALSA may then interact with complement molecules such as C1q, MBL and the ficolins to regulate complement activation.

appears that a link exists between a diminished SALSA function and predisposition to $\mathrm{CD}$. Interestingly, the development of paediatric IBD has also been linked to impaired function of the lectin and classical pathways of complement. Disease was associated with a higher frequency of the MBL2 gene and two separate C4 genes (one C4A and one C4B), all leading to a deficient phenotype (Bak-Romaniszyn et al., 2011; Kolho et al., 2015). This highlights the relevance of the complement regulating properties of SALSA in this environment, and suggests an additional mechanism for a detrimental outcome of expressing a functionally impaired SALSA molecule.

SALSA is part of the mucosal inflammatory response. The protein expression is induced by several factors that are altered in the local environment of chronic inflammatory conditions, including IL-22, NOD2 and TLR4 signalling. This may explain the observation of increased SALSA levels in the affected mucosa. Normal SALSA functions include both anti-microbial defence as well as interactions with the epithelium. The latter includes a negative feedback mechanism on TLR4 signalling in response to microbial components. Despite the increased expression of SALSA, certain isoforms with diminished anti-microbial binding or faulty interaction with the epithelial negative feedback loop could thus propagate mucosal inflammation and ultimately worsen IBD (see Fig. 3).

\subsection{SALSA and complement in cystic fibrosis}

Cystic fibrosis (CF) is another example where a damaged mucosal barrier leads to opportunistic pathogens infecting the host. CF is the most commonly inherited genetic disease in persons of European descent affecting 1 in 2500 newborns (Sallenave, 2014). The major symptoms are observed in the lungs and digestive tract where cycles of exocrine gland obstruction, infection and inflammation lead to destruction of the mucosal tissue (Rowe et al., 2005; Sallenave, 2014).

SALSA is upregulated in the pancreas and small intestine of the CFTR knockout mouse indicating a possible protective role in this CF model (De Lisle et al., 1998; De Lisle et al., 2001; Norkina et al., 2004). A similar increased expression is observed for a number of complement components in the epithelium and in mucosal secretions (Norkina et al., 2004; Sass et al., 2015). The specific role of these anti-microbial molecules in the setting of $\mathrm{CF}$ is not clear. In the lung, a hallmark of CF is colonization by Pseudomonas aeruginosa and $S$. aureus. While SALSA has been shown to agglutinate $S$. aureus, no effect was observed on $P$. aeruginosa (Jumblatt et al., 2006). However, both microbes activate TLR4 signalling, and could thus lead to increased SALSA expression as described in IBD. Interestingly, impaired monocyte phagocytosis of $P$. aeruginosa was shown to be complement-dependent in CF (Van de Weert-van Leeuwen et al., 2013). Currently no studies have addressed the role of genetic variations in the SALSA molecule and the development of CF. However, the functional relation between SALSA and disease would be interesting to address in the future.

The composition and viscosity of the mucus is a confounding factor in the development of CF. Overexpression of a large glycoprotein, such as SALSA, may affect the fluidity of the mucosal secretions directly. A high amount of SALSA may thus lead to an exacerbated obstruction of the luminal space, thus further propagating the pathogenesis (De Lisle et al., 1998). Together with the inflammatory effects of SALSA, the biochemical properties of the molecule could thus be detrimental to disease progression in $\mathrm{CF}$ patients. 


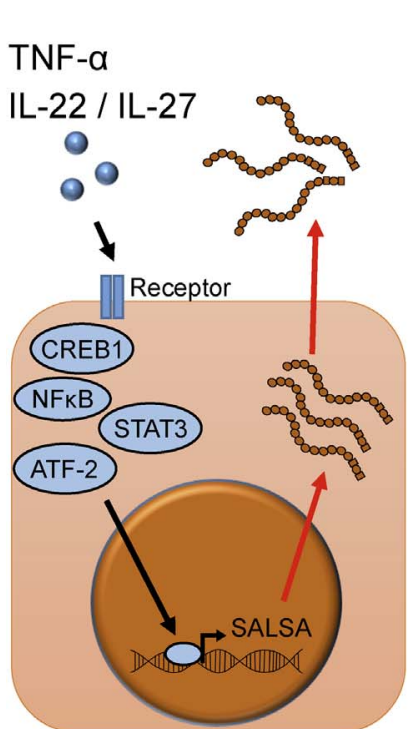

\section{Stimulation of SALSA expression}

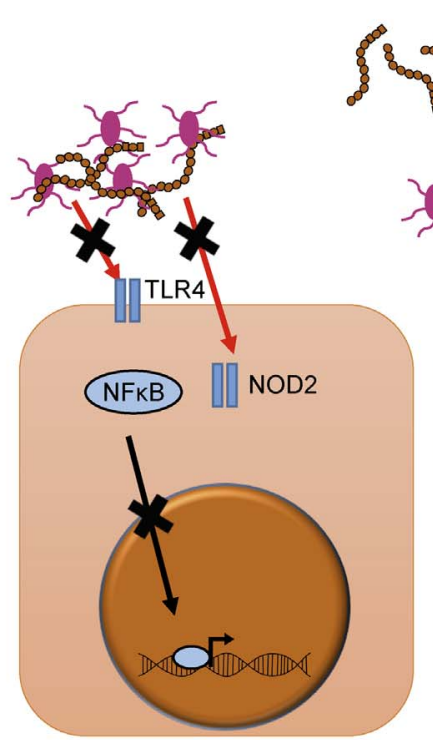

\section{SALSA expression blocks TLR4 and NOD2 signaling}

Fig. 3. SALSA expression in inflamed epithelium. The chronic inflammatory setting of Crohn's disease is associated with increased levels of the pro-inflammatory cytokines TNF- $\alpha$, IL-22 and IL-27. These cytokines activate signalling pathways in the epithelial cells and through STAT3, NFKB, CREB and ATF-2 stimulate the expression of SALSA. Once secreted, SALSA agglutinates and clears microbes, leading to a decreased activation of TLR4 and NOD2 signalling. A SNP in the promoter region of SALSA leads to diminished SALSA expression. Other mutations lead to the expression of certain deletion variants of SALSA, lacking several SRCR domains. Both types of mutations diminish the function of SALSA, and both types of mutations have been associated with Crohn's disease. It would appear, that the lack of negative feedback on the TLR4/NOD2 signalling is a likely mechanism by which a lack of functional SALSA may exacerbate inflammation at the mucosal surface, and thus propagate the development of Crohn's disease.

\section{SALSA in non-mucosal tissues}

Although most research has focused on the expression of SALSA at the mucosal surfaces, new data is accumulating describing the expression of the protein also in the parenteral tissues. The expression of SALSA has been described in the heart, liver, skin, tonsils and placenta (Mollenhauer et al., 2001; Muller et al., 2009; Reichhardt et al., 2016). In the heart tissue sporadic SALSA expression was found both in the myocytes and in the endothelial cells (Muller et al., 2009, 2013). Furthermore, we recently found SALSA expressed in the maternal decidual endothelium during the first trimester of pregnancy. At term SALSA was found intracellularly in the placental syncytiotrophoblast layer and in distinct extracellular formations called fibrinoids (Reichhardt et al., 2016). The expression of SALSA in both heart and placenta was scattered, suggesting that the expression is inducible, rather than constitutive. In the heart valves of patients with endocarditis the expression of SALSA was increased specifically in the areas of infected valves in association with colonizing bacteria (Muller et al., 2009). A similar local up-regulation was observed in areas of amyloid deposits in patients suffering from cardiac amyloidosis (Muller et al., 2013). The epithelial cells of the biliary duct have been found to express SALSA, albeit weakly. However, under certain pathological conditions such as hepatolithiasis the expression was induced (Sasaki et al., 2002).

It appears that danger signals and possibly certain inflammatory or immunological stimuli may induce SALSA expression in tissues as well as in the mucosal epithelium. A recent study showed that SALSA deposits into the extracellular matrix of vascular endothelium and affects the proliferation, angiogenesis and vascular repair (Muller et al., 2012). Placental angiogenesis is an ongoing process in the first trimester placenta. Failure of angiogenesis leads to hypoxia and is a key feature of several pregnancy complications (Jauniaux et al., 2000, 2003). For the local capillaries and vessels this presents a "danger signal" for which a response could be the expression of SALSA. This hypothesis corresponds well to results from a mouse study where SALSA was found to be an important ECM protein involved in both endothelial cell adhesion, migration, proliferation and reparative angiogenesis (Muller et al., 2012). Furthermore, it was shown that SALSA knock-out mice showed an impaired recovery from ischemic hind-limb injury suggesting that SALSA is involved in the process of endothelial cell response to hypoxia (Muller et al., 2012).
To this date, SALSA has not been shown as a soluble protein in blood plasma. Rather, it appears, that the molecule is immediately scavenged, and kept from being free in blood, e.g. by deposition into the endothelial ECM (Muller et al., 2012; Reichhardt et al., 2016). However, the recent descriptions of SALSA expression in non-mucosal tissues, such as heart and placenta, immediately puts the SALSA molecule into an environment, where it could interact with complement components directly following expression (Muller et al., 2009; Reichhardt et al., 2016). SALSA deposition has been found to be associated with fibrinrich formations in both placental and heart tissue (Muller et al., 2009; Reichhardt et al., 2016). We recently described partial co-localization of SALSA and C1q in fibrinoid formations of the human placenta (Reichhardt et al., 2016). In contrast, no co-localization was found between SALSA and complement in the heart tissue (Muller et al., 2013). Although not all SALSA expression was co-localized with complement components, the interaction observed in the placenta is the first evidence that SALSA and complement interact in vivo (Reichhardt et al., 2016). Understanding the physiological outcome of the SALSAcomplement interactions, both on the mucosal surfaces and in the parenteral tissues is an exciting issue for future research.

\section{SALSA - a central player in the mucosal immunological network?}

Above we have described how SALSA interacts with the epithelial cell surface, a multitude of bacterial and viral invaders, endothelial cells, complement proteins, IgA and several other innate immune defence molecules. Differently expressed isoforms of SALSA may have stronger affinity for some molecules rather than others, making some interactions more relevant than others in a biological setting. Yet the prospect remains that SALSA is a molecule with an ability to influence many types of cellular interactions and innate immunity. As such, it is not surprising that the range of described involvement in both biological processes and diseases is continuously expanding.

The overall function of SALSA at the mucosal surfaces appears clear. The molecule agglutinates and removes invading micro-organisms, while dampening the general inflammatory response. Simultaneously, it maintains the integrity of the mucosal surface barrier by supporting the homeostasis of the epithelial layer (Ligtenberg et al., 2010; Madsen et al., 2010). Yet, the many versions of the SALSA molecule expressed, 
and the multiple interactions it partakes in, also mean that it is a candidate for dysfunction in disease. This is particularly possible with certain isoforms that have been linked to an exacerbated immunological response, as seen in Crohn's disease. We are only beginning to understand the multiple forms the protein presents in. Likewise, we are only beginning to understand the impact on the mucosal immunity of the individual. Most of the effort's in relation to SALSA research have focused on diseases related to the intestines, but SALSA may play equally important roles in diseases like cystic fibrosis and even asthma. Future research may show us how this molecule may both be important for increasing the effectiveness of immune responses, as well as limiting damaging inflammatory processes and combatting infections. In a society where chronic inflammatory conditions are on the rise, a future knowledge of the complex interactions of SALSA may prove to be essential.

\section{Acknowledgements}

This study was supported by The Finnish Cultural Foundation, The Sigrid Jusélius Foundation, The Academy of Finland, The Signe and Ane Gyllenberg Foundation and Helsinki University Hospital Funds.

\section{References}

Ahmad, T., Armuzzi, A., Bunce, M., Mulcahy-Hawes, K., Marshall, S.E., Orchard, T.R., Crawshaw, J., Large, O., de Silva, A., Cook, J.T., Barnardo, M., Cullen, S., Welsh, K.I., Jewell, D.P., 2002. The molecular classification of the clinical manifestations of Crohn's disease. Gastroenterology 4, 854-866.

Andersen, C.B., Moestrup, S.K., 2014. How calcium makes endocytic receptors attractive. Trends Biochem. Sci. 2, 82-90.

Andoh, A., Zhang, Z., Inatomi, O., Fujino, S., Deguchi, Y., Araki, Y., Tsujikawa, T., Kitoh, K., Kim-Mitsuyama, S., Takayanagi, A., Shimizu, N., Fujiyama, Y., 2005. Interleukin22 , a member of the IL-10 subfamily, induces inflammatory responses in colonic subepithelial myofibroblasts. Gastroenterology 3, 969-984.

Bak-Romaniszyn, L., Szala, A., Sokolowska, A., Mierzwa, G., Czerwionka-Szaflarska, M., Swierzko, A.S., Zeman, K., Cedzynski, M., 2011. Mannan-binding lectin deficiency in pediatric patients with inflammatory bowel disease. Scand. J. Gastroenterol. 10, 1275-1278.

Bally, I., Rossi, V., Lunardi, T., Thielens, N.M., Gaboriaud, C., Arlaud, G.J., 2009. Identification of the C1q-binding sites of human $\mathrm{C} 1 \mathrm{r}$ and $\mathrm{C} 1 \mathrm{~s}$ : a refined three-dimensional model of the C1 complex of complement. J. Biol. Chem. 29, 19340-19348.

Bearfield, C., Davenport, E.S., Sivapathasundaram, V., Allaker, R.P., 2002. Possible association between amniotic fluid micro-organism infection and microflora in the mouth. BJOG 5, 527-533.

Bikker, F.J., Ligtenberg, A.J., Nazmi, K., Veerman, E.C., van't Hof, W., Bolscher, J.G., Poustka, A., Nieuw Amerongen, A.V., Mollenhauer, J., 2002. Identification of the bacteria-binding peptide domain on salivary agglutinin (gp-340/DMBT1), a member of the scavenger receptor cysteine-rich superfamily. J. Biol. Chem. 35, 32109-32115.

Bikker, F.J., Ligtenberg, A.J., End, C., Renner, M., Blaich, S., Lyer, S., Wittig, R., van't Hof, W., Veerman, E.C., Nazmi, K., de Blieck-Hogervorst, J.M., Kioschis, P., Nieuw Amerongen, A.V., Poustka, A., Mollenhauer, J., 2004. Bacteria binding by DMBT1/ SAG/gp-340 is confined to the VEVLXXXXW motif in its scavenger receptor cysteinerich domains. J. Biol. Chem. 46, 47699-47703.

Boackle, R.J., Connor, M.H., Vesely, J., 1993. High molecular weight non-immunoglobulin salivary agglutinins (NIA) bind C1Q globular heads and have the potential to activate the first complement component. Mol. Immunol. 3, 309-319.

Boackle, R.J., 1991. The interaction of salivary secretions with the human complement system-a model for the study of host defense systems on inflamed mucosal surfaces. Crit. Rev. Oral Biol. Med. 3, 355-367.

Brady, L.J., Piacentini, D.A., Crowley, P.J., Oyston, P.C., Bleiweis, A.S., 1992. Differentiation of salivary agglutinin-mediated adherence and aggregation of mutans streptococci by use of monoclonal antibodies against the major surface adhesin P1. Infect. Immun. 3, 1008-1017.

Braidotti, P., Nuciforo, P.G., Mollenhauer, J., Poustka, A., Pellegrini, C., Moro, A., Bulfamante, G., Coggi, G., Bosari, S., Pietra, G.G., 2004. DMBT1 expression is downregulated in breast cancer. BMC Cancer 46.

Brand, S., Beigel, F., Olszak, T., Zitzmann, K., Eichhorst, S.T., Otte, J.M., Diepolder, H., Marquardt, A., Jagla, W., Popp, A., Leclair, S., Herrmann, K., Seiderer, J., Ochsenkuhn, T., Goke, B., Auernhammer, C.J., Dambacher, J., 2006. IL-22 is increased in active Crohn's disease and promotes proinflammatory gene expression and intestinal epithelial cell migration. Am. J. Physiol. Gastrointest. Liver Physiol. 4, G827-G838.

Brittan, J.L., Nobbs, A.H., 2015. Group B Streptococcus pili mediate adherence to salivary glycoproteins. Microbes Infect. 17, 360-368.

Chappell, P.E., Garner, L.I., Yan, J., Metcalfe, C., Hatherley, D., Johnson, S., Robinson, C.V., Lea, S.M., Brown, M.H., 2015. Structures of CD6 and its ligand CD166 give insight into their interaction. Structure 8, 1426-1436.

Chu, H., Khosravi, A., Kusumawardhani, I.P., Kwon, A.H., Vasconcelos, A.C., Cunha, L.D.,
Mayer, A.E., Shen, Y., Wu, W.L., Kambal, A., Targan, S.R., Xavier, R.J., Ernst, P.B., Green, D.R., McGovern, D.P., Virgin, H.W., Mazmanian, S.K., 2016. Gene-microbiota interactions contribute to the pathogenesis of inflammatory bowel disease. Science 6289, 1116-1120.

Cone, R.A., 2009. Barrier properties of mucus. Adv. Drug Deliv. Rev. 2, 75-85.

Crouch, E.C., 2000. Surfactant protein-D and pulmonary host defense. Respir. Res. 2, 93-108.

De Lisle, R.C., Petitt, M., Isom, K.S., Ziemer, D., 1998. Developmental expression of a mucinlike glycoprotein (MUCLIN) in pancreas and small intestine of CF mice. Am. J. Physiol. 2 (Pt. 1), G219-G227.

De Lisle, R.C., Isom, K.S., Ziemer, D., Cotton, C.U., 2001. Changes in the exocrine pancreas secondary to altered small intestinal function in the CF mouse. Am. J. Physiol. Gastrointest. Liver Physiol. 4, G899-G906.

Demuth, D.R., Golub, E.E., Malamud, D., 1990. Streptococcal-host interactions: structural and functional analysis of a Streptococcus sanguis receptor for a human salivary glycoprotein. J. Biol. Chem. 13, 7120-7126.

Dethlefsen, L., McFall-Ngai, M., Relman, D.A., 2007. An ecological and evolutionary perspective on human-microbe mutualism and disease. Nature 7164, 811-818.

Diegelmann, J., Olszak, T., Goke, B., Blumberg, R.S., Brand, S., 2012. A novel role for interleukin-27 (IL-27) as mediator of intestinal epithelial barrier protection mediated via differential signal transducer and activator of transcription (STAT) protein signaling and induction of antibacterial and anti-inflammatory proteins. J. Biol. Chem. 1, 286-298.

Diegelmann, J., Czamara, D., Le Bras, E., Zimmermann, E., Olszak, T., Bedynek, A., Goke, B., Franke, A., Glas, J., Brand, S., 2013. Intestinal DMBT1 expression is modulated by Crohn's disease-associated IL23R variants and by a DMBT1 variant which influences binding of the transcription factors CREB1 and ATF-2. PLoS One 11, e77773.

Dunkelberger, J.R., Song, W.C., 2010. Complement and its role in innate and adaptive immune responses. Cell Res. 1, 34-50.

End, C., Lyer, S., Renner, M., Stahl, C., Ditzer, J., Holloschi, A., Kuhn, H.M., Flammann, H.T., Poustka, A., Hafner, M., Mollenhauer, J., Kioschis, P., 2005. Generation of a vector system facilitating cloning of DMBT1 variants and recombinant expression of functional full-length DMBT1. Protein Expr. Purif. 2, 275-286.

End, C., Bikker, F., Renner, M., Bergmann, G., Lyer, S., Blaich, S., Hudler, M., Helmke, B., Gassler, N., Autschbach, F., Ligtenberg, A.J., Benner, A., Holmskov, U., Schirmacher, P., Nieuw Amerongen, A.V., Rosenstiel, P., Sina, C., Franke, A., Hafner, M., Kioschis, P., Schreiber, S., Poustka, A., Mollenhauer, J., 2009. DMBT1 functions as patternrecognition molecule for poly-sulfated and poly-phosphorylated ligands. Eur. J. Immunol. 3, 833-842.

Ericson, T., Rundegren, J., 1983. Characterization of a salivary agglutinin reacting with a serotype c strain of Streptococcus mutans. Eur. J. Biochem. 2, 255-261.

Eriksson, C., Frangsmyr, L., Danielsson Niemi, L., Loimaranta, V., Holmskov, U., Bergman, T., Leffler, H., Jenkinson, H.F., Stromberg, N., 2007. Variant size- and glycoforms of the scavenger receptor cysteine-rich protein gp-340 with differential bacterial aggregation. Glycoconj. J. 2-3, 131-142.

Feinberg, H., Uitdehaag, J.C., Davies, J.M., Wallis, R., Drickamer, K., Weis, W.I., 2003. Crystal structure of the CUB1-EGF-CUB2 region of mannose-binding protein associated serine protease-2. EMBO J. 10, 2348-2359.

Freeley, S., Kemper, C., Le Friec, G., 2016. The ins and outs of complement-driven immune responses. Immunol. Rev. 1, 16-32.

Fukui, H., Sekikawa, A., Tanaka, H., Fujimori, Y., Katake, Y., Fujii, S., Ichikawa, K., Tomita, S., Imura, J., Chiba, T., Fujimori, T., 2011. DMBT1 is a novel gene induced by IL-22 in ulcerative colitis. Inflamm. Bowel Dis. 5, 1177-1188.

Garcia Rodriguez, L.A., Ruigomez, A., Panes, J., 2006. Acute gastroenteritis is followed by an increased risk of inflammatory bowel disease. Gastroenterology 6, 1588-1594.

Groenink, J., Walgreen-Weterings, E., van 't Hof, W., Veerman, E.C., Nieuw Amerongen, A.V., 1999. Cationic amphipathic peptides, derived from bovine and human lactoferrins, with antimicrobial activity against oral pathogens. FEMS Microbiol. Lett. 2, $217-222$.

Gronborg, M., Bunkenborg, J., Kristiansen, T.Z., Jensen, O.N., Yeo, C.J., Hruban, R.H., Maitra, A., Goggins, M.G., Pandey, A., 2004. Comprehensive proteomic analysis of human pancreatic juice. J. Proteome Res. 5, 1042-1055.

Gunput, S.T., Ligtenberg, A.J., Terlouw, B., Brouwer, M., Veerman, E.C., Wouters, D., 2015. Complement activation by salivary agglutinin is secretor status dependent. Biol. Chem. 1, 35-43.

Gunput, S.T., Wouters, D., Nazmi, K., Cukkemane, N., Brouwer, M., Veerman, E.C., Ligtenberg, A.J., 2016. Salivary agglutinin is the major component in human saliva that modulates the lectin pathway of the complement system. Innate Immun. 4, 257-265.

Hakansson, K., Reid, K.B., 2000. Collectin structure: a review. Protein Sci. 9, 1607-1617.

Hamm, C.M., Reimers, M.A., McCullough, C.K., Gorbe, E.B., Lu, J., Gu, C.C., Li, E., Dieckgraefe, B.K., Gong, Q., Stappenbeck, T.S., Stone, C.D., Dietz, D.W., Hunt, S.R., 2010. NOD2 status and human ileal gene expression. Inflamm. Bowel Dis. 10, 1649-1657.

Han, L., Monne, M., Okumura, H., Schwend, T., Cherry, A.L., Flot, D., Matsuda, T., Jovine, L., 2010. Insights into egg coat assembly and egg-sperm interaction from the X-ray structure of full-length ZP3. Cell 3, 404-415.

Hartshorn, K.L., White, M.R., Mogues, T., Ligtenberg, T., Crouch, E., Holmskov, U., 2003 Lung and salivary scavenger receptor glycoprotein-340 contribute to the host defense against influenza A viruses. Am. J. Physiol. Lung Cell. Mol. Physiol. 5, L1066-L1076.

Hartshorn, K.L., Ligtenberg, A., White, M.R., Van Eijk, M., Hartshorn, M., Pemberton, L., Holmskov, U., Crouch, E., 2006. Salivary agglutinin and lung scavenger receptor cysteine-rich glycoprotein 340 have broad anti-influenza activities and interactions with surfactant protein D that vary according to donor source and sialylation. Biochem. J. 545-553.

Haukioja, A., Loimaranta, V., Tenovuo, J., 2008. Probiotic bacteria affect the composition 
of salivary pellicle and streptococcal adhesion in vitro. Oral Microbiol. Immunol. 4, 336-343.

Henriksen, M.L., Brandt, J., Andrieu, J.P., Nielsen, C., Jensen, P.H., Holmskov, U., Jorgensen, T.J., Palarasah, Y., Thielens, N.M., Hansen, S., 2013. Heteromeric complexes of native collectin kidney 1 and collectin liver 1 are found in the circulation with MASPs and activate the complement system. J. Immunol. 12, 6117-6127.

Hoek, G.H., Brand, H.S., Veerman, E.C., Amerongen, A.V., 2002. Toothbrushing affects the protein composition of whole saliva. Eur. J. Oral Sci. 6, 480-481.

Holmskov, U., Lawson, P., Teisner, B., Tornoe, I., Willis, A.C., Morgan, C., Koch, C., Reid, K.B., 1997. Isolation and characterization of a new member of the scavenger receptor superfamily, glycoprotein-340 (gp-340), as a lung surfactant protein-D binding molecule. J. Biol. Chem. 21, 13743-13749.

Holmskov, U., Mollenhauer, J., Madsen, J., Vitved, L., Gronlund, J., Tornoe, I., Kliem, A., Reid, K.B., Poustka, A., Skjodt, K., 1999. Cloning of gp-340, a putative opsonin receptor for lung surfactant protein D. Proc. Natl. Acad. Sci. U. S. A. 19, 10794-10799.

Holmskov, U., Thiel, S., Jensenius, J.C., 2003. Collections and ficolins: humoral lectins of the innate immune defense. Annu. Rev. Immunol. 547-578.

Hugot, J.P., Chamaillard, M., Zouali, H., Lesage, S., Cezard, J.P., Belaiche, J., Almer, S., Tysk, C., O'Morain, C.A., Gassull, M., Binder, V., Finkel, Y., Cortot, A., Modigliani, R., Laurent-Puig, P., Gower-Rousseau, C., Macry, J., Colombel, J.F., Sahbatou, M., Thomas, G., 2001. Association of NOD2 leucine-rich repeat variants with susceptibility to Crohn's disease. Nature 6837, 599-603.

Jauniaux, E., Watson, A.L., Hempstock, J., Bao, Y.P., Skepper, J.N., Burton, G.J., 2000. Onset of maternal arterial blood flow and placental oxidative stress. A possible factor in human early pregnancy failure. Am. J. Pathol. 6, 2111-2122.

Jauniaux, E., Hempstock, J., Greenwold, N., Burton, G.J., 2003. Trophoblastic oxidative stress in relation to temporal and regional differences in maternal placental blood flow in normal and abnormal early pregnancies. Am. J. Pathol. 1, 115-125.

Jenkinson, H.F., Demuth, D.R., 1997. Structure, function and immunogenicity of streptococcal antigen I/II polypeptides. Mol. Microbiol. 2, 183-190.

Jimenez, E., Marin, M.L., Martin, R., Odriozola, J.M., Olivares, M., Xaus, J., Fernandez, L., Rodriguez, J.M., 2008. Is meconium from healthy newborns actually sterile? Res. Microbiol. 3, 187-193.

Jonasson, A., Eriksson, C., Jenkinson, H.F., Kallestal, C., Johansson, I., Stromberg, N., 2007. Innate immunity glycoprotein gp-340 variants may modulate human susceptibility to dental caries. BMC Infect. Dis. 57.

Jumblatt, M.M., Imbert, Y., Young Jr., W.W., Foulks, G.N., Steele, P.S., Demuth, D.R., 2006. Glycoprotein 340 in normal human ocular surface tissues and tear film. Infect. Immun. 7, 4058-4063.

Kang, W., Reid, K.B., 2003. DMBT1: a regulator of mucosal homeostasis through the linking of mucosal defense and regeneration? FEBS Lett. 1-3, 21-25.

Kang, W., Nielsen, O., Fenger, C., Madsen, J., Hansen, S., Tornoe, I., Eggleton, P., Reid, K.B., Holmskov, U., 2002. The scavenger receptor, cysteine-rich domain-containing molecule gp-340 is differentially regulated in epithelial cell lines by phorbol ester. Clin. Exp. Immunol. 3, 449-458.

Kim, T.H., Lee, S.H., Lee, H.M., Jung, H.H., Lee, S.H., Cho, W.S., Cinn, Y.G., Choe, H., Kim, M.P., Yoo, I.O., Hwang, H.Y., 2007. Increased expression of glycoprotein 340 in the ethmoid sinus mucosa of patients with chronic sinusitis. Arch. Otolaryngol. Head. Neck. Surg. 11, 1111-1114.

Kolho, K.L., Paakkanen, R., Lepistö, A., Wennerström, A., Meri, S., Lokki, M.L., 2015. Novel associations between major histocompatibility complex and pediatric onset inflammatory bowel disease. J. Pediatr. Gastroenterol. Nutr. 62, 567-572.

Leito, J.T., Ligtenberg, A.J., Nazmi, K., de Blieck-Hogervorst, J.M., Veerman, E.C., Nieuw Amerongen, A.V., 2008. A common binding motif for various bacteria of the bacteriabinding peptide SRCRP2 of DMBT1/gp-340/salivary agglutinin. Biol. Chem. 9, 1193-1200.

Leito, J.T., Ligtenberg, A.J., van Houdt, M., van den Berg, T.K., Wouters, D., 2011. The bacteria binding glycoprotein salivary agglutinin (SAG/gp340) activates complement via the lectin pathway. Mol. Immunol. 185-190.

Levy, O., 2007. Innate immunity of the newborn: basic mechanisms and clinical correlates. Nat. Rev. Immunol. 5, 379-390.

Ligtenberg, A.J., Veerman, E.C., Nieuw Amerongen, A.V., 2000. A role for Lewis a antigens on salivary agglutinin in binding to Streptococcus mutans. Antonie Van Leeuwenhoek 1, 21-30.

Ligtenberg, T.J., Bikker, F.J., Groenink, J., Tornoe, I., Leth-Larsen, R., Veerman, E.C., Nieuw Amerongen, A.V., Holmskov, U., 2001. Human salivary agglutinin binds to lung surfactant protein-D and is identical with scavenger receptor protein gp-340. Biochem. J. 243-248.

Ligtenberg, A.J., Bikker, F.J., De Blieck-Hogervorst, J.M., Veerman, E.C., Nieuw Amerongen, A.V., 2004. Binding of salivary agglutinin to IgA. Biochem. J. 159-164.

Ligtenberg, A.J., Veerman, E.C., Nieuw Amerongen, A.V., Mollenhauer, J., 2007. Salivary agglutinin/glycoprotein-340/DMBT1: a single molecule with variable composition and with different functions in infection inflammation and cancer. Biol. Chem. 12, $1275-1289$.

Ligtenberg, A.J., Karlsson, N.G., Veerman, E.C., 2010. Deleted in malignant brain tumors1 protein (DMBT1): a pattern recognition receptor with multiple binding sites. Int. J. Mol. Sci. 12, 5212-5233.

Loimaranta, V., Jakubovics, N.S., Hytonen, J., Finne, J., Jenkinson, H.F., Stromberg, N., 2005. Fluid- or surface-phase human salivary scavenger protein gp340 exposes different bacterial recognition properties. Infect. Immun. 4, 2245-2252.

Madsen, J., Tornoe, I., Nielsen, O., Lausen, M., Krebs, I., Mollenhauer, J., Kollender, G., Poustka, A., Skjodt, K., Holmskov, U., 2003. CRP-ductin, the mouse homologue of gp340 /deleted in malignant brain tumors 1 (DMBT1), binds gram-positive and gramnegative bacteria and interacts with lung surfactant protein D. Eur. J. Immunol. 8, 2327-2336.

Madsen, J., Mollenhauer, J., Holmskov, U., 2010. Review: gP-340/DMBT1 in mucosal innate immunity. Innate Immun. 3, 160-167.

Madsen, J., Sorensen, G.L., Nielsen, O., Tornoe, I., Thim, L., Fenger, C., Mollenhauer, J., Holmskov, U., 2013. A variant form of the human deleted in malignant brain tumor 1 (DMBT1) gene shows increased expression in inflammatory bowel diseases and interacts with dimeric trefoil factor 3 (TFF3). PLoS One 5, e64441.

Markiewski, M.M., Nilsson, B., Ekdahl, K.N., Mollnes, T.E., Lambris, J.D., 2007. Complement and coagulation: strangers or partners in crime? Trends Immunol. 4, 184-192.

Meri, S., Jarva, H., 1998. Complement regulation. Vox Sang. 291-302.

Meri, S., 2016. Self-nonself discrimination by the complement system. FEBS Lett. 15, 2418-2434.

Mitoma, M., Oho, T., Shimazaki, Y., Koga, T., 2001. Inhibitory effect of bovine milk lactoferrin on the interaction between a streptococcal surface protein antigen and human salivary agglutinin. J. Biol. Chem. 21, 18060-18065.

Mollenhauer, J., Wiemann, S., Scheurlen, W., Korn, B., Hayashi, Y., Wilgenbus, K.K., von Deimling, A., Poustka, A., 1997. DMBT1, a new member of the SRCR superfamily, on chromosome 10q25.3-26.1 is deleted in malignant brain tumours. Nat. Genet. 1, 32-39.

Mollenhauer, J., Holmskov, U., Wiemann, S., Krebs, I., Herbertz, S., Madsen, J., Kioschis, P., Coy, J.F., Poustka, A., 1999. The genomic structure of the DMBT1 gene: evidence for a region with susceptibility to genomic instability. Oncogene 46, 6233-6240.

Mollenhauer, J., Herbertz, S., Holmskov, U., Tolnay, M., Krebs, I., Merlo, A., Schroder, H.D., Maier, D., Breitling, F., Wiemann, S., Grone, H.J., Poustka, A., 2000. DMBT1 encodes a protein involved in the immune defense and in epithelial differentiation and is highly unstable in cancer. Cancer Res. 6, 1704-1710.

Mollenhauer, J., Herbertz, S., Helmke, B., Kollender, G., Krebs, I., Madsen, J., Holmskov, U., Sorger, K., Schmitt, L., Wiemann, S., Otto, H.F., Grone, H.J., Poustka, A., 2001. Deleted in Malignant Brain Tumors 1 is a versatile mucin-like molecule likely to play a differential role in digestive tract cancer. Cancer Res. 24, 8880-8886.

Mollenhauer, J., Helmke, B., Muller, H., Kollender, G., Krebs, I., Wiemann, S., Holmskov, U., Madsen, J., Otto, H.F., Poustka, A., 2002a. An integrative model on the role of DMBT1 in epithelial cancer. Cancer Detect. Prev. 4, 266-274.

Mollenhauer, J., Helmke, B., Muller, H., Kollender, G., Lyer, S., Diedrichs, L., Holmskov, U., Ligtenberg, T., Herbertz, S., Krebs, I., Wiemann, S., Madsen, J., Bikker, F., Schmitt, L., Otto, H.F., Poustka, A., 2002b. Sequential changes of the DMBT1 expression and location in normal lung tissue and lung carcinomas. Genes. Chromosomes Cancer 2, 164-169.

Mollenhauer, J., Muller, H., Kollender, G., Lyer, S., Diedrichs, L., Helmke, B., Holmskov, U., Ligtenberg, T., Herbertz, S., Krebs, I., Madsen, J., Bikker, F., Schmitt, L., Wiemann, S., Scheurlen, W., Otto, H.F., von Deimling, A., Poustka, A., 2002c. The SRCR/SID region of DMBT1 defines a complex multi-allele system representing the major basis for its variability in cancer. Genes. Chromosomes Cancer 3, 242-255.

Molodecky, N.A., Soon, I.S., Rabi, D.M., Ghali, W.A., Ferris, M., Chernoff, G., Benchimol, E.I., Panaccione, R., Ghosh, S., Barkema, H.W., Kaplan, G.G., 2012. Increasing incidence and prevalence of the inflammatory bowel diseases with time, based on systematic review. Gastroenterology 1, 46-54 e42; quiz e30.

Muller, H., Renner, M., Helmke, B.M., End, C., Weiss, C., Poeschl, J., Mollenhauer, J., 2009. Deleted in Malignant Brain Tumors 1 is up-regulated in bacterial endocarditis and binds to components of vegetations. J. Thorac. Cardiovasc. Surg. 3, 725-732.

Muller, H., Hu, J., Popp, R., Schmidt, M.H., Muller-Decker, K., Mollenhauer, J., Fisslthaler, B., Eble, J.A., Fleming, I., 2012. Deleted in malignant brain tumors 1 is present in the vascular extracellular matrix and promotes angiogenesis. Arterioscler. Thromb. Vasc. Biol. 2, 442-448.

Muller, H., Renner, M., Bergmann, F., Mechtersheimer, G., Weiss, C., Poeschl, J., Helmke, B.M., Mollenhauer, J., 2013. Cardiac amyloidosis induces up-regulation of deleted in malignant brain tumors 1 (DMBT1). Cardiovasc. Pathol. 3, 195-202.

Nagashunmugam, T., Malamud, D., Davis, C., Abrams, W.R., Friedman, H.M., 1998. Human submandibular saliva inhibits human immunodeficiency virus type 1 infection by displacing envelope glycoprotein gp120 from the virus. J. Infect. Dis. 6, 1635-1641.

Negut, E.A., Balteanu, M., Ionescu, G., Bancescu, A., Iliescu, A., Skaug, N., 2007. Control of blood-transmitted infections in dentistry. Roum. Arch. Microbiol. Immunol. 26-36.

Norkina, O., Kaur, S., Ziemer, D., De Lisle, R.C., 2004. Inflammation of the cystic fibrosis mouse small intestine. Am. J. Physiol. Gastrointest. Liver Physiol. 6, G1032-G1041.

Ogura, Y., Bonen, D.K., Inohara, N., Nicolae, D.L., Chen, F.F., Ramos, R., Britton, H., Moran, T., Karaliuskas, R., Duerr, R.H., Achkar, J.P., Brant, S.R., Bayless, T.M., Kirschner, B.S., Hanauer, S.B., Nunez, G., Cho, J.H., 2001a. A frameshift mutation in NOD2 associated with susceptibility to Crohn's disease. Nature 6837, 603-606.

Ogura, Y., Bonen, D.K., Inohara, N., Nicolae, D.L., Chen, F.F., Ramos, R., Britton, H., Moran, T., Karaliuskas, R., Duerr, R.H., Achkar, J.P., Brant, S.R., Bayless, T.M., Kirschner, B.S., Hanauer, S.B., Nunez, G., Cho, J.H., 2001b. A frameshift mutation in NOD2 associated with susceptibility to Crohn's disease. Nature 6837, 603-606.

Oho, T., Yu, H., Yamashita, Y., Koga, T., 1998. Binding of salivary glycoprotein-secretory immunoglobulin A complex to the surface protein antigen of Streptococcus mutans. Infect. Immun. 1, 115-121.

Oho, T., Bikker, F.J., Nieuw Amerongen, A.V., Groenink, J., 2004. A peptide domain of bovine milk lactoferrin inhibits the interaction between streptococcal surface protein antigen and a salivary agglutinin peptide domain. Infect. Immun. 10, 6181-6184.

Persson, C.G., Erjefalt, I., Alkner, U., Baumgarten, C., Greiff, L., Gustafsson, B., Luts, A., Pipkorn, U., Sundler, F., Svensson, C., 1991. Plasma exudation as a first line respiratory mucosal defence. Clin. Exp. Allergy 1, 17-24.

Phillips, A.E., Toth, J., Dodds, A.W., Girija, U.V., Furze, C.M., Pala, E., Sim, R.B., Reid, K.B., Schwaeble, W.J., Schmid, R., Keeble, A.H., Wallis, R., 2009. Analogous interactions in initiating complexes of the classical and lectin pathways of complement. J. Immunol. 12, 7708-7717.

Polley, S., Louzada, S., Forni, D., Sironi, M., Balaskas, T., Hains, D.S., Yang, F., Hollox, 
E.J., 2015. Evolution of the rapidly mutating human salivary agglutinin gene (DMBT1) and population subsistence strategy. Proc. Natl. Acad. Sci. U. S. A 112 5105-5110.

Polley, S., Prescott, N., Nimmo, E., Veal, C., Vind, I., Munkholm, P., Fode, P., Mansfield, J., Skyt Andersen, P., Satsangi, J., G Mathew, C., Hollox, E.J., 2016. Copy number variation of scavenger-receptor cysteine-rich domains within DMBT1 and Crohn's disease. Eur. J. Hum. Genet. 24, 1294-1300.

Porter, C.K., Tribble, D.R., Aliaga, P.A., Halvorson, H.A., Riddle, M.S., 2008. Infectious gastroenteritis and risk of developing inflammatory bowel disease. Gastroenterology 3, 781-786.

Prakobphol, A., Xu, F., Hoang, V.M., Larsson, T., Bergstrom, J., Johansson, I., Frangsmyr, L., Holmskov, U., Leffler, H., Nilsson, C., Boren, T., Wright, J.R., Stromberg, N., Fisher, S.J., 2000. Salivary agglutinin, which binds Streptococcus mutans and Helicobacter pylori, is the lung scavenger receptor cysteine-rich protein gp-340. J. Biol. Chem. 51, 39860-39866.

Prakobphol, A., Boren, T., Ma, W., Zhixiang, P., Fisher, S.J., 2005. Highly glycosylated human salivary molecules present oligosaccharides that mediate adhesion of leukocytes and Helicobacter pylori. Biochemistry 6, 2216-2224.

Purushotham, S., Deivanayagam, C., 2014. The calcium-induced conformation and glycosylation of scavenger-rich cysteine repeat (SRCR) domains of glycoprotein 340 influence the high affinity interaction with antigen I/II homologs. J. Biol. Chem. 32, 21877-21887.

Reichhardt, M.P., Meri, S., 2016. SALSA: a regulator of the early steps of complement activation on mucosal surfaces. Front. Immunol. 85.

Reichhardt, M.P., Loimaranta, V., Thiel, S., Finne, J., Meri, S., Jarva, H., 2012. The salivary scavenger and agglutinin binds MBL and regulates the lectin pathway of complement in solution and on surfaces. Front. Immunol. 205.

Reichhardt, M.P., Jarva, H., de Been, M., Rodriguez, J.M., Jimenez Quintana, E., Loimaranta, V., Meindert de Vos, W., Meri, S., 2014. The salivary scavenger and agglutinin in early life: diverse roles in amniotic fluid and in the infant intestine. J. Immunol. 193, 5240-5248.

Reichhardt, M.P., Jarva, H., Lokki, A.I., Laivuori, H., FINNPEC study group, Vuorela, P., Loimaranta, V., Glasner, A., Siwetz, M., Huppertz, B., Meri, S., 2016. The salivary scavenger and agglutinin (SALSA) in healthy and complicated pregnancy. PLoS One 2, e0147867.

Renner, M., Bergmann, G., Krebs, I., End, C., Lyer, S., Hilberg, F., Helmke, B., Gassler, N., Autschbach, F., Bikker, F., Strobel-Freidekind, O., Gronert-Sum, S., Benner, A., Blaich, S., Wittig, R., Hudler, M., Ligtenberg, A.J., Madsen, J., Holmskov, U., Annese, V., Latiano, A., Schirmacher, P., Amerongen, A.V., D'Amato, M., Kioschis, P., Hafner, M., Poustka, A., Mollenhauer, J., 2007. DMBT1 confers mucosal protection in vivo and a deletion variant is associated with Crohn's disease. Gastroenterology 5, 1499-1509.

Ricklin, D., Hajishengallis, G., Yang, K., Lambris, J.D., 2010. Complement: a key system for immune surveillance and homeostasis. Nat. Immunol. 9, 785-797.

Rodamilans, B., Munoz, I.G., Bragado-Nilsson, E., Sarrias, M.R., Padilla, O., Blanco, F.J., Lozano, F., Montoya, G., 2007. Crystal structure of the third extracellular domain of CD5 reveals the fold of a group B scavenger cysteine-rich receptor domain. J. Biol. Chem. 17, 12669-12677.

Roldan, M.L., Marini, P.E., 2013. First evidence of the interaction between deleted in malignant brain tumor 1 and galectin-3 in the mammalian oviduct. Histochem. Cell Biol. 141, 181-190.

Ronellenfitsch, S., Weiss, C., Frommhold, D., Koch, L., Mollenhauer, J., Poeschl, J., Muller, H., 2012. High DMBT1 concentrations in breast milk correlate with increased risk of infection in preterm and term neonates. BMC Pediatr (157-2431-12-157).

Rooks, M.G., Garrett, W.S., 2016. Gut microbiota, metabolites and host immunity. Nat. Rev. Immunol. 6, 341-352.

Roos, A., Bouwman, L.H., van Gijlswijk-Janssen, D.J., Faber-Krol, M.C., Stahl, G.L., Daha, M.R., 2001. Human IgA activates the complement system via the mannan-binding lectin pathway. J. Immunol. 5, 2861-2868.

Rosenstiel, P., Sina, C., End, C., Renner, M., Lyer, S., Till, A., Hellmig, S., Nikolaus, S., Folsch, U.R., Helmke, B., Autschbach, F., Schirmacher, P., Kioschis, P., Hafner, M., Poustka, A., Mollenhauer, J., Schreiber, S., 2007. Regulation of DMBT1 via NOD2 and TLR4 in intestinal epithelial cells modulates bacterial recognition and invasion. J. Immunol. 12, 8203-8211.

Rossez, Y., Coddeville, B., Elass, E., Quinchon, J.F., Vidal, O., Corfield, A.P., Gosset, P., Lacroix, J.M., Michalski, J.C., Robbe-Masselot, C., 2011. Interaction between DMBT1 and galectin 3 is modulated by the structure of the oligosaccharides carried by DMBT1. Biochimie 3, 593-603.

Rowe, S.M., Miller, S., Sorscher, E.J., 2005. Cystic fibrosis. N. Engl. J. Med. 19, 1992-2001.

Rundegren, J., Arnold, R.R., 1987. Differentiation and interaction of secretory immunoglobulin A and a calcium-dependent parotid agglutinin for several bacterial strains. Infect. Immun. 2, 288-292.

Sallenave, J.M., 2014. Phagocytic and signaling innate immune receptors: are they dysregulated in cystic fibrosis in the fight against Pseudomonas aeruginosa? Int. J. Biochem. Cell Biol. 103-107.

Sarrias, M.R., Gronlund, J., Padilla, O., Madsen, J., Holmskov, U., Lozano, F., 2004. The Scavenger Receptor Cysteine-Rich (SRCR) domain: an ancient and highly conserved protein module of the innate immune system. Crit. Rev. Immunol. 1, 1-37.

Sasaki, H., Betensky, R.A., Cairncross, J.G., Louis, D.N., 2002. DMBT1 polymorphisms: relationship to malignant glioma tumorigenesis. Cancer Res. 6, 1790-1796.
Sass, L.A., Hair, P.S., Perkins, A.M., Shah, T.A., Krishna, N.K., Cunnion, K.M., 2015. Complement effectors of inflammation in cystic fibrosis lung fluid correlate with clinical measures of disease. PLoS One 12, e0144723.

Schulz, B.L., Oxley, D., Packer, N.H., Karlsson, N.G., 2002. Identification of two highly sialylated human tear-fluid DMBT1 isoforms: the major high-molecular-mass glycoproteins in human tears. Biochem. J. 511-520.

Singh, P.K., Parsek, M.R., Greenberg, E.P., Welsh, M.J., 2002. A component of innate immunity prevents bacterial biofilm development. Nature 6888, 552-555.

Sonesson, M., Ericson, D., Kinnby, B., Wickstrom, C., 2011. Glycoprotein 340 and sialic acid in minor-gland and whole saliva of children adolescents, and adults. Eur. J. Oral Sci. 6, 435-440.

Stoddard, E., Cannon, G., Ni, H., Kariko, K., Capodici, J., Malamud, D., Weissman, D., 2007. gp340 expressed on human genital epithelia binds HIV-1 envelope protein and facilitates viral transmission. J. Immunol. 5, 3126-3132.

Stoddard, E., Ni, H., Cannon, G., Zhou, C., Kallenbach, N., Malamud, D., Weissman, D., 2009. Gp340 promotes transcytosis of human immunodeficiency virus type 1 in genital tract-derived cell lines and primary endocervical tissue. J. Virol. 17, 8596-8603.

Sugimoto, K., Ogawa, A., Mizoguchi, E., Shimomura, Y., Andoh, A., Bhan, A.K., Blumberg, R.S., Xavier, R.J., Mizoguchi, A., 2008. IL-22 ameliorates intestinal inflammation in a mouse model of ulcerative colitis. J. Clin. Invest. 2, 534-544.

Thim, L., Mortz, E., 2000. Isolation and characterization of putative trefoil peptide receptors. Regul. Pept. 61-68.

Thornton, D.J., Davies, J.R., Kirkham, S., Gautrey, A., Khan, N., Richardson, P.S., Sheehan, J.K., 2001. Identification of a nonmucin glycoprotein (gp-340) from a purified respiratory mucin preparation: evidence for an association involving the MUC5B mucin. Glycobiology 11, 969-977.

Tino, M.J., Wright, J.R., 1999. Glycoprotein-340 binds surfactant protein-A (SP-A) and stimulates alveolar macrophage migration in an SP-A-independent manner. Am. J. Respir. Cell Mol. Biol. 4, 759-768.

Tlaskalova-Hogenova, H., Stepankova, R., Hudcovic, T., Tuckova, L., Cukrowska, B., Lodinova-Zadnikova, R., Kozakova, H., Rossmann, P., Bartova, J., Sokol, D., Funda, D.P., Borovska, D., Rehakova, Z., Sinkora, J., Hofman, J., Drastich, P., Kokesova, A., 2004. Commensal bacteria (normal microflora): mucosal immunity and chronic inflammatory and autoimmune diseases. Immunol. Lett. 97-108.

Van Limbergen, J., Wilson, D.C., Satsangi, J., 2009. The genetics of Crohn's disease. Annu. Rev. Genomics Hum. Genet. 89-116.

Van de Weert-van Leeuwen, P.B., Van Meegen, M.A., Speirs, J.J., Pals, D.J., Rooijakkers, S.H., Van der Ent, C.K., Terheggen-Lagro, S.W., Arets, H.G., Beekman, J.M., 2013. Optimal complement-mediated phagocytosis of Pseudomonas aeruginosa by monocytes is cystic fibrosis transmembrane conductance regulator-dependent. Am. J. Respir. Cell Mol. Biol. 3, 463-470.

van Lookeren Campagne, M., Wiesmann, C., Brown, E.J., 2007. Macrophage complement receptors and pathogen clearance. Cell. Microbiol. 9, 2095-2102.

Wallis, R., Mitchell, D.A., Schmid, R., Schwaeble, W.J., Keeble, A.H., 2010. Paths reunited: initiation of the classical and lectin pathways of complement activation. Immunobiology 1, 1-11.

Walport, M.J., 2001. Complement. First of two parts. N. Engl. J. Med. 14, 1058-1066.

Ward, P.P., Paz, E., Conneely, O.M., 2005. Multifunctional roles of lactoferrin: a critical overview. Cell Mol. Life Sci. 22, 2540-2548.

Wetsel, R.A., 1995. Structure, function and cellular expression of complement anaphy latoxin receptors. Curr. Opin. Immunol. 1, 48-53.

Wheeler, G.L., Miranda-Saavedra, D., Barton, G.J., 2008. Genome analysis of the unicellular green alga Chlamydomonas reinhardtii Indicates an ancient evolutionary origin for key pattern recognition and cell-signaling protein families. Genetics 1, 193-197.

White, M.R., Crouch, E., Vesona, J., Tacken, P.J., Batenburg, J.J., Leth-Larsen, R., Holmskov, U., Hartshorn, K.L., 2005. Respiratory innate immune proteins differentially modulate the neutrophil respiratory burst response to influenza A virus. Am. J. Physiol. Lung Cell. Mol. Physiol. 4, L606-L616.

White, M.R., Helmerhorst, E.J., Ligtenberg, A., Karpel, M., Tecle, T., Siqueira, W.L., Oppenheim, F.G., Hartshorn, K.L., 2009. Multiple components contribute to ability of saliva to inhibit influenza viruses. Oral Microbiol. Immunol. 1, 18-24.

Wickstrom, C., Christersson, C., Davies, J.R., Carlstedt, I., 2000. Macromolecular organization of saliva: identification of 'insoluble' MUC5B assemblies and non-mucin proteins in the gel phase. Biochem. J. 421-428.

Wu, Z., Van Ryk, D., Davis, C., Abrams, W.R., Chaiken, I., Magnani, J., Malamud, D., 2003. Salivary agglutinin inhibits HIV type 1 infectivity through interaction with viral glycoprotein 120. AIDS Res. Hum. Retroviruses 3, 201-209.

Xu, A.T., Li, Y., Zhao, D., Shen, J., Xu, X.T., Qiao, Y.Q., Zhu, M.M., Wang, T.R., Cui, Y., Ai, L.Y., Ran, Z.H., 2015. High suppressor of cytokine signaling-3 expression impairs STAT3-dependent protective effects of interleukin-22 in ulcerative colitis in remission. Inflamm. Bowel Dis. 2, 241-250.

Young, A., Rykke, M., Smistad, G., Rolla, G., 1997. On the role of human salivary micellelike globules in bacterial agglutination. Eur. J. Oral Sci. 5 (Pt. 2), 485-494.

Yu, M., Vajdy, M., 2010. Mucosal HIV transmission and vaccination strategies through oral compared with vaginal and rectal routes. Expert Opin. Biol. Ther. 8, 1181-1195.

Zenewicz, L.A., Yancopoulos, G.D., Valenzuela, D.M., Murphy, A.J., Stevens, S., Flavell, R.A., 2008. Innate and adaptive interleukin-22 protects mice from inflammatory bowel disease. Immunity 6, 947-957. 